BLS 35, No 1 2009. DOI: http://dx.doi.org/10.3765/bls.v35i1.3623

(published by the Berkeley Linguistics Society and the Linguistic Society of America)

\title{
Tonal Mapping in Cantonese Vocative Reduplication
}

\author{
ALAN C. L. YU \\ University of Chicago
}

\section{Introduction: Tonal (Non-)Transfer in Reduplication}

Research on reduplication has traditionally focused on the segmental mapping between the reduplicant and the base. Until recently, little attention is paid to the mapping of prosodic features, such as tone, stress, or pitch accent. Downing (2003) is a noted exception. She examined the behavior of tone in the reduplicative morphology of several Bantu languages and observed that there are three common patterns of tonal correspondence in verbal reduplication in these languages. The first type involves a match in the tone of the RED(duplicant) and its Base (tonal transfer; e.g., Chichewa (1a)). The second pattern is understood to be the result of markedness motivated mismatch (the emergence of the unmarked; TETU). Whether the first or second half of a RED+Base complex retains the underlying tone pattern depends on which half is the reduplicant. For example, in $\mathrm{KiHehe}$, the marked $\mathrm{H}$ tone is realized on the second half $(1 \mathrm{~b})$, while it is realized on the first half in Shona (1c). The third pattern reflects the Base stem (BStem) tone being realized on the entire RED+Base complex form. Thus in Kikerewe, if an $\mathrm{H}$ tone is realized on the first two syllables in the unreduplicated form, then an $\mathrm{H}$ tone is also realized on the first two syllable of the reduplicative complex. If $\mathrm{H}$ is on the final two syllables in the unreduplicated verb, then the $\mathrm{H}$ tone is realized on the final two syllables of the reduplicative complex (Odden 1996).

(1) Verbal reduplication (Downing 2003)
Unreduplicated
'X repeatedly'
a. Chichewa phikits-á 'really cook!'
phikits-á-phikits-á
b. KiHehe si-tu=[déeña 'we won't cut'
si-tu $=[$ deña-déeña
c. Shona
-tóresá 'I didn't make take'
-tóresá-toresa
d. Kikerewe ku-[káláanga 'to fry'
ku-[káláanga-kalaanga
m-[baz-ílé 'I counted (yesterday)'
m-[bazile-bazílé

The case of Kikerewe is particularly interesting since, despite the claim that tonal mapping is at the level of the reduplicative complex, the tonal pattern of the unreduplicated verb nonetheless appears faithfully on at least one part of the 
reduplicative complex. That is, there is segmental and tonal matching between the unreduplicated form and one part of the reduplicative complex. A summary of the range of tonal matching in reduplication found in Downing's study is given in (2). For the sake of clarity, I shall use $\mathrm{R}_{\mathrm{A}}$ and $\mathrm{R}_{\mathrm{B}}$ to refer to the left and right members of the reduplicative complex respectively.

(2) Typology of tonal (mis)match in reduplication ${ }^{1}$

$\begin{array}{lll}\mathrm{R}_{\mathrm{A}} \mathrm{R}_{\mathrm{B}} & \text { Total matching } & \text { Chichewa } \\ \underline{\mathrm{R}}_{A} \mathrm{R}_{\mathrm{B}} & \text { Left-bound mismatch } & \text { KiHehe } \\ \mathrm{R}_{\mathrm{A}} \underline{\mathrm{R}_{B}} & \text { Right-bound mismatch } & \text { Shona } \\ \underline{\mathrm{R}}_{\underline{A}} \underline{R}_{\mathrm{B}} / \mathrm{R}_{\mathrm{A}} \underline{\mathrm{R}}_{\underline{B}} & \text { Mismatch obviation } & \text { Kikerewe } \\ \underline{\mathrm{R}}_{\underline{A}} \underline{R}_{\underline{B}} & \text { Total mismatch } & ?\end{array}$

This paper investigates a case of tonal mismatch in Cantonese, arguing that tonal mapping in Cantonese also occurs at the level of the reduplicative complex, similar to Kikerewe. However, unlike Kikerewe, the tonal pattern of the reduplicative complex may bear no relationship to the tone of its unreduplicated counterpart. The paper is organized as follows: I begin with an introduction of the basic pattern of tonal mismatch in Cantonese reduplicative vocatives (Section 1). Section 2 explores potential motivations for the tonal mismatch, arguing ultimately that tonal mismatch is not phonologically-driven. Section 3 sketches a morphological-doubling analysis of vocative reduplication in this language.

\section{Cantonese Vocative Reduplication}

Cantonese is within the Yue subfamily of Chinese. It has a six tone systems, although traditional Cantonese linguistic literature treats tones occurring on obstruent-final syllable (CVO) as distinct tones. Since no segmental alternation is involved in any of the examples below, for the sake of convenience, Cantonese examples are transliterated in the Jyutping romanicization system designed by the Linguistics Society of Hong Kong for Cantonese. Tones are indicated using the Jyutping tone numbers (3).

(3) Cantonese tone system

$\begin{array}{lll}\text { Jyutping }^{2} & \text { Chao tone number } & \\ 1 & 53 \sim 55 & \text { CVV, CVN, CVO } \\ 2 & 25 & \text { CVV, CVN } \\ 3 & 33 & \text { CVV, CVN, CVO } \\ 4 & 21 & \text { CVV, CVN } \\ 5 & 23 & \text { CVV, CVN } \\ 6 & 22 & \text { CVV, CVN, CVO }\end{array}$

\footnotetext{
${ }^{1}$ Underline indicates unfaithful tonal realization between the input and the output.

${ }^{2}$ All tone numbers will be prefixed with "T" in text (e.g., T2, T4, etc.) for ease of reference.
} 


\section{Tonal Mapping in Cantonese Vocative Reduplication}

Cantonese has multiple methods for forming vocatives. The method of interests here is vocative formation via total segmental reduplication. Such reduplicative vocatives often exhibit tone changes that result in tonal mismatch. Two notions of tonal mismatch are relevant here. Vocative reduplicative complexes always exhibit tonal mismatches between the base and the reduplicant (BR-mismatch), although, non-tone-changing alternatives are often possible. ${ }^{3}$ There are also mismatches between the input and the output reduplicative complex. Three patterns of IO-mismatch at the tonal level are observed. As shown in (4), when the tone of the source syllable is $\mathrm{T} 3$ or $\mathrm{T} 4, \mathrm{R}_{\mathrm{A}}$ retains the source tone, but $\mathrm{R}_{\mathrm{B}}$ has $\mathrm{T} 1$ or T2. Let us refer to this Pattern 1.

$\begin{array}{llll}\text { Pattern 1: Reduplication with } \mathrm{R}_{\mathrm{A}} \underline{\mathrm{R}_{B}} \text { mismatch } & \\ \text { Base } & \text { with tone change } & \text { without tone change } & \text { Gloss } \\ \text { po4 } & \text { po4po2 } & \text { po4po4 } & \text { 'old woman' } \\ \text { fei4 } & \text { fei4fei2 } & \text { *fei4fei4 } & \text { 'fatty' } \\ \text { ye4 } & \text { ye4ye2 } & \text { ?ye4ye4 } & \text { 'paternal grandfather' } \\ \text { mou4 } & \text { mou4 } \underline{\text { mou1 }} & \text { ?mou4mou4 } & \text { 'little hairy thing' } \\ \text { taai3 } & \text { taai3taai2 } & \text { *taai3taai3 } & \text { 'wife' }\end{array}$

In Pattern $2, \mathrm{R}_{\mathrm{B}}$ retains the source tones (i.e. $\mathrm{T} 1$ or $\mathrm{T} 2$ ), but $\mathrm{R}_{\mathrm{A}}$ carries $\mathrm{T} 4$.

\begin{tabular}{|c|c|c|c|}
\hline $\begin{array}{l}\text { Pattern } \\
\text { bong1 }\end{array}$ & $\begin{array}{l}\text { : Reduplicatic } \\
\text { bong4bong1 }\end{array}$ & $\begin{array}{l}\underline{\mathrm{R}}_{\mathrm{A}} \mathrm{R}_{\mathrm{B}} \text { mismatch } \\
\text { bong1bong } 1\end{array}$ & 'little Bong' \\
\hline gung1 & gung4 gung1 & gunglgung1 & 'old man' \\
\hline maa1 & maa4maa1 & maalmaal & 'mother' \\
\hline go1 & go4go1 & golgo1 & 'elder brother' \\
\hline zai2 & zai4zai2 & *zai2zai2 & 'son’' \\
\hline bi1 & bi4bi1 & *bilbil & 'baby' \\
\hline ze 1 & ze4ze1 & ze1ze1/zi2zi2 & 'elder sister' \\
\hline
\end{tabular}

Pattern 3 characterizes instances of total tonal mismatch; when the source tone is $T 5$ or $T 6$, neither $R_{A}$ nor $R_{B}$ retains the source tone. $R_{A}$ has $T 4$, while $R_{B}$ has $T 2$.

$\begin{array}{llll}\text { Pattern } & \text { 3: Reduplication with total tonal faithfulness } \\ \text { mui6 } & \underline{\text { mui4mui2 }} & \text { mui6mui6 } & \text { 'younger sister' } \\ \text { dai6 } & \underline{\text { dai4dai2 }} & \text { dai6dai6 } & \text { 'younger brother' } \\ \text { nai5 } & \underline{\text { nai4nai2 }} & \text { *nai5nai5 } & \text { 'husband's mother' } \\ \text { noei5 } & \underline{\text { noei4noei2 }} & \text { *noei5noei5 } & \text { 'daughter' }\end{array}$

There also exist several intrinsically reduplicated vocatives (i.e. the reduplicative complex has no non-reduplicated counterpart; (7)). Of relevance here is the fact

\footnotetext{
${ }^{3}$ Total reduplication with faithful tonal mapping is primarily a feature of the literary and more formal register. It is commonly used in read speech and broadcast speech.
} 
Alan C. L. Yu

that the tone patterns of such intrinsically reduplicated vocatives follow the $\mathrm{T} 4\{\mathrm{~T} 1 / \mathrm{T} 2\}$ tonal templates observed in (4)-(6).

$$
\begin{array}{ll}
\text { Baseless reduplication } \\
\text { di4di2 } & \text { 'little boy' } \\
\text { zoe4zoe1 } & \text { 'child's penis' } \\
\text { gu4gu1 } & \text { 'child's penis' }
\end{array}
$$

The tonal transfer properties of reduplicative vocatives present a curious puzzle: Why does tone change take place sometimes on the second syllable (4), on the first syllable (5), or on both syllables (6), all resulting in tonal mismatches between the reduplicant and the base? More puzzling is the fact that, except for source syllables with T3, the outcomes of the different tone changes converge in a sequence of $\mathrm{T} 4$ followed by either $\mathrm{T} 1$ or $\mathrm{T} 2$. Why should this be? The next section considers two possible explanations.

\section{Why T4T1/T2?}

In this section, I review two potential explanations for non-tonal transfer in reduplicative vocatives in Cantonese: Changed Tone (Section 2.1) and the emergence of the unmarked (Section 2.2).

\subsection{Changed Tone in Cantonese}

Many morphological constructions in Cantonese are signified either solely or partly by a change to $\mathrm{T} 1 / \mathrm{T} 2$ from non-T1/T2 syllables. Traditional descriptive linguistic literature of Cantonese refers to this process as Pinjam 變音, 'changed

\begin{tabular}{|c|c|}
\hline Verb & Gloss \\
\hline sou3 & 'to sweep' \\
\hline pong6 & 'to weigh' \\
\hline mo4 & 'to grind' \\
\hline daan6 & 'to pluck' \\
\hline waa6 & 'to tell' \\
\hline yau4 & 'to grease' \\
\hline
\end{tabular}
tone.' For example, (8) shows an instance of deverbal nominalization signaled solely by a tone change to $\mathrm{T} 2{ }^{4}$

$\begin{array}{ll}\text { b. Noun } & \text { Gloss } \\ \text { sou2 } & \text { 'a broom' } \\ \text { pong2 } & \text { 'a scale' } \\ \text { mo2 } & \text { 'a grind' } \\ \text { daan2 } & \text { 'a missile' } \\ \text { waa2 } & \text { 'an utterance' } \\ \text { yau2 } & \text { 'oil' }\end{array}$

Another word formation strategy that requires tone change to T2 is diminutive formation.

\footnotetext{
${ }^{4}$ Historically Cantonese has a high-falling tone (53) that changes to high-level (i.e. T1) as a result of pinjam. A recent merger of 53 and 55 (T1) renders this tone change opaque today.
} 
Tonal Mapping in Cantonese Vocative Reduplication

(9)

\begin{tabular}{|c|c|c|c|c|}
\hline \multirow{9}{*}{$\begin{array}{ll}\text { a. } & \text { toi4 } \\
\text { kwan4 } \\
\text { geng3 }\end{array}$} & 'stage, terrace' & $\rightarrow$ & toi2 & 'table' \\
\hline & 'skirt' & $\rightarrow$ & wai4kwan2 & 'apron' \\
\hline & 'mirror' & $\rightarrow$ & ngaan5geng2 & 'eyeglasses' \\
\hline & 'girl, woman' & $\rightarrow$ & mou5neoi2 & 'call girl' \\
\hline & 'girl, woman' & $\rightarrow$ & sau1neoi2 & 'nun’ \\
\hline & ‘cockroach’' & $\sim$ & gaat6zaat2 & \\
\hline & ‘butterfly’ & $\sim$ & wu4dip2 & \\
\hline & ‘duck’ & $\sim$ & aаp2 & \\
\hline & 'pigeon, squab' & $\sim$ & gaap2 & \\
\hline
\end{tabular}

Of particular relevance here is the fact that certain vocative/familiar name formation strategies are accompanied by tone change as well. For example, when the vocative prefix a3- or lou3-is attached to a name, the tone of that name may become T2 (10).

(10) Cantonese familiar name formation (Yip 1992; Bauer and Benedict 1997)

$\begin{array}{lll}\text { a. } & \text { yip6 } & \text { a3yip2 } \\ & \text { can4 } & \text { a3can2 } \\ \text { zoeng1 } & \text { a3zoeng1 } \\ \text { b. } & \text { yueng4 } & \text { lou3yueng2 } \\ & \text { lei3 } & \text { lou3lei2 } \\ \text { wong4 } & \text { lou3wong2 } \\ \text { daai6 } & \text { lou3dai2 }\end{array}$

In part because of examples such as (8)-(10), traditional descriptive linguistic literature of Cantonese often attributes tonal mismatches in reduplicative vocatives to the general tendency of tone change to $\mathrm{T} 2$. While it seems plausible to attribute tone change to $T 2$ on $R_{B}$ to Cantonese's preference for tone change to $T 1$ or $T 2$, this only accounts for half the problem. Tone change to $\mathrm{T} 4$ on $\mathrm{R}_{\mathrm{A}}$ remains a puzzle. Further complicating the picture is the fact that, as illustrated by (11), the type of tonal mismatch in reduplicative vocatives is not a general property of tonal mapping in Cantonese reduplication. Attentuative reduplication in Cantonese adjectives also requires tonal change to $\mathrm{T} 2$ on $\mathrm{R}_{\mathrm{B}}$ (underlined). However, no concomitant tone change on $R_{\mathrm{A}}$ is needed even when the source syllable carries $\mathrm{T} 5$ or $\mathrm{T} 6$.

(11) Attentuative reduplication

$\begin{array}{llll}\text { geng1 } & \text { 'afraid' } & \text { geng1 geng1dei2 } & \text { 'a bit fearful' } \\ \text { coen2 } & \text { 'stupid' } & \text { coen2 } \underline{\text { coen2dei2 }} & \text { 'a little stupid' } \\ \text { man3 } & \text { 'edgy' } & \text { man3man2dei2 } & \text { 'a bit close to the edgy' } \\ \text { so4 } & \text { 'silly' } & \text { 'so4so2dei2' } & \text { 'a bit silly' } \\ \text { nuen5 } & \text { 'warm' } & \text { nuen5nuen2dei2 } & \text { 'a bit warm' } \\ \text { mun6 } & \text { 'boring' } & \text { mun6mun2dei2 } & \text { 'a bit boring' } \\ \text { lok6 } & \text { 'green' } & \text { lok6lok2dei2 } & \text { 'greenish' }\end{array}$


Alan C. L. Yu

In light of the examples in (11), the grammar of Cantonese must provide some construction-specific means to derive the tonal patterns of the reduplicative vocatives apart from other forms of reduplication in the language.

Recent literature on reduplication suggests that mismatches in reduplicative faithfulness may be the results of the emergence of the unmarked (McCarthy and Prince 1994, 1995; TETU). The next section explores the possibility of analyzing changes to $T 4$ on $R_{A}$ and $T 1 / T 2$ on $R_{B}$ as the effects of TETU in tone-prominence interaction.

\subsection{The Emergence of the Unmarked?}

This section considers an explanation of the T4T1/T2 templatic effect from the perspective of prominence-driven tonal assignment. The argument for prominence and metrical structures being relevant in Cantonese comes from the need for a disyllabic iambic output template in Cantonese vocative formation.

Yip (1992) argues for the need of a disyllabic iambic output template in Cantonese based on examples such as those in (10). She points out that "[t]hese Cantonese data...can be analyzed as the result of matching a monosyllabic input to a bisyllabic iambic output template, forcing the provision of an extra syllable, and a H-tone prominence marker at the boundary of the foot. The iambic template here is a prosodic target" (p. 29). That the extra syllable /a/ appears as the left rather than the right syllable of the iamb foot is argued to be the result of the head position (i.e. the second syllable) being filled by the source syllable. The fact that the head position carries a high tone is interpreted as a means to increase the prominence of the second syllable.

For the sake of argument, let us assume that the iambic template is what drives vocative reduplication, it is conceivable then that tone change to T4 on the first syllable and to T1/T2 on the second may be analyzed as a consequence of prominence-driven tone assignment (de Lacy 2002). For the sake of argument, let us also posit the structurally-determined tonal prominence scales in (12). The first scale (12a) captures the idea that high-toned syllables (T1 or T2) are preferred in the head position over non-high-toned syllables. The second scale (12b) suggests that $\mathrm{T} 4$ is the preferred tone in non-head positions.

(12) a. Structurally-determined tonal prominence scale 1 in Cantonese $\mathrm{HD} /\{\mathrm{T} 1, \mathrm{~T} 2\}>>\mathrm{HD} / \neg \mathrm{T}\{1,2\}$

b. Structurally-determined tonal prominence scale 2 in Cantonese NON-HD/T4 >> NON-HD/ $\neg$ T4

Given the constraints in (13), the fact that $\mathrm{T} 4$ emerges as the tone on $\mathrm{R}_{\mathrm{A}}$ when the input syllable carries $\mathrm{T} 2$ can be explained as an instance of the emergence of the unmarked. That is, as long as the input T2 has a correspondent in the output word (cf. Struijke 2000; see the failure of (14d)), the remainder of the reduplicative complex may differ in its tonal specification from the input tone provided that tonal mismatch leads to satisfaction of tonal markedness constraints that dominate 


\section{Tonal Mapping in Cantonese Vocative Reduplication}

BR-faithfulness (i.e. (14a) is chosen the winner over (14b) and (14c) because (14b) and (14c) fatally violate UseT12 and UseT4 respectively).

(13) IDENT-ASSOC $\mathrm{WD}$

(ID- $\left.\mathrm{T}_{\mathrm{WD}}\right)$

If there is an association between $x$ and tone $\mathrm{T}$ in the input, then there is an association between $x^{\prime}$ and $\mathrm{T}^{\prime}$ in the output word, where $\mathrm{x}^{\prime}$ and $\mathrm{T}$ ' are the correspondents of $x$ and T respectively (cf. Myers 1997:863; de Lacy 2002:16, Struijke 2000)

IDENT-ASSOC $_{\mathrm{BR}}$ If there is an association between $x$ and tone $\mathrm{T}$ in the $\left(\mathrm{ID}-\mathrm{T}_{\mathrm{BR}}\right)$ base, then there is an association between $x$ ' and $\mathrm{T}^{\prime}$ in the reduplicant, where $\mathrm{x}^{\prime}$ and $\mathrm{T}$ ' are the correspondents of $x$ and T respectively

${ }^{*} \mathrm{HD} / \neg \mathrm{T}\{1,2\} \quad$ Assign a violation for each occurrence of a head (UseT12)

$*$ NON-HD/ $\neg \mathrm{T} 4 \quad$ Assign a violation for each occurrence of a non-head (UseT4) syllable with a non-T4 tone.

(14)

\begin{tabular}{|ll||l|l:l|l|}
\hline input & RED, /T2/ & ID-T $_{\mathrm{WD}}$ & UseT12 & UseT4 & ID-T $_{\mathrm{BR}}$ \\
\hline \hline a. & $(\mathrm{T} 4-\mathrm{T} 2)^{5}$ & & & & $*$ \\
\hline b. & $(\mathrm{T} 2-\underline{\mathrm{T} 2})$ & & $* !$ & & \\
\hline c. & $(\mathrm{T} 2-\underline{\mathrm{T}} 4)$ & & & $* !$ & $*$ \\
\hline d. & $(\mathrm{T} 4-\mathrm{T} 4)$ & $* !$ & $*$ & & \\
\hline
\end{tabular}

Similarly, when the input syllable carries T4, the fully faithful candidate (15b) is rejected because the head syllable carries T4. Gratuitous non-tonal transfers are ruled out because of the effects of dominating tone-prominence constraints (15b) $\&(15 c)$ or input-word faithfulness (15d).

\begin{tabular}{|c|c|c|c|c|c|}
\hline input & RED, /T4/ & ID-T ${ }_{W D}$ & UseT12 & UseT4 & ID-T $T_{B R}$ \\
\hline a. & (T4-T2) & & & & $*$ \\
\hline b. & (T4-T4) & & $* !$ & & \\
\hline c. & (T2-T4) & & $* !$ & $*$ & \\
\hline d. & (T2-T2) & $* !$ & & $*$ & \\
\hline
\end{tabular}

While this TETU analysis is appealing from the perspective of being able to tie mismatches in tonal mapping to the interaction between metrical prominence and tonal assignment, such an account runs into several theoretical and empirical problems. To begin with, the TETU analysis developed thus far fails to generate

${ }^{5}$ The head position of a foot is underlined. It is assumed here that the output form must be an iamb; candidates not conforming to this output foot structure will not be considered further. The segmental content of the input and the output candidates are left out for the sake of ease of reference since segmental information does not interact with tonal assignment. 
the right output when the input syllable carries a tone that is neither T2 nor T4. As shown in (16), for example, when the input syllable carries T6, the dominance of ID-T ${ }_{\mathrm{WD}}$ over UseT12 and UseT12 dictates that the input tone must be faithfully realized somewhere in the output. Total tonal mismatch, the attested option, is ruled out prematurely (see failure of (16a)). Note that demoting ID-T $\mathrm{WD}_{\mathrm{W}}$ is not an option as it would erroneously predict that all disyllabic words in Cantonese have $\mathrm{T} 1$ or $\mathrm{T} 2$ in the second syllable and T4 in the first.

\begin{tabular}{|c|c|c|c|c|c|}
\hline input & $\mathrm{RED}, / \mathrm{T} 6 /$ & ID-T ${ }_{W D}$ & UseT12 & UseT4 & ID- $T_{B R}$ \\
\hline $\mathrm{a}$. & (T4-T2) & $* !$ & & & $*$ \\
\hline$\Rightarrow b$. & (T6-T6) & & $* !$ & & \\
\hline c. & (T6-T2) & & & $* !$ & * \\
\hline c. & (T4-T6) & & $* !$ & & * \\
\hline
\end{tabular}

Furthermore, the unmarkedness of T4 is dubious. (17) shows the type and token frequencies of Cantonese tones reported in Leung et al.'s (2004) recent corpus study of Cantonese. ${ }^{6}$ T4 is not the most frequent tone in Cantonese either in terms of token or type frequency. The most common tone in both token and type frequencies is T1. The second most frequent tone is T3.

(17) Type and token frequencies of Cantonese tones (Leung et al. 2004)

$\begin{array}{lrlrr}\text { Tone } & & & \text { Token } & \text { Type } \\ 55 & \text { T1: } 25,193 & \text { T7:4,952 } & 30,145 & 442 \\ 25 & \text { T2: } 23,346 & & 23,346 & 310 \\ 33 & \text { T3: } 23,279 & \text { T8: } 3,309 & 27,002 & 399 \\ 21 & \text { T4: } 15,898 & & 15,898 & 271 \\ 23 & \text { T5: } 15,098 & & 15,098 & 140 \\ 22 & \text { T6: } 25,218 & \text { T9: } 4,442 & 29,660 & 361 \\ \text { Total } & & & 141,149 & 1923\end{array}$

The unmarked nature of T4 is further cast in doubt in light of the type of default tonal assignment evidenced in loanword adaptation in Cantonese. Silverman (1992) reports that disyllabic forms which receive final stress in English enter Cantonese with a H tone (T1 or T2) on the final syllable and a M tone (T3) on the initial syllable (18a). All final syllables that are not perceived as possessing a tone in English surface with a pitch rise (18b) and (18d).

\footnotetext{
${ }^{6}$ The HKCAC corpus contains eight hours of recordings of phone-in programs and forums on the radio of HK, including 69 native speakers in addition to the program hosts. The corpus contains approximately 140,000 syllable-character units.
} 
(18) Stress-to-tone in English loanwords (Silverman 1992:304)

$\begin{array}{lll} & \text { English } & \text { Cantonese } \\ \text { a. } & \text { buffet } & \text { pou3fei1 } \\ & \text { cigar } & \text { syut3gaa1 } \\ \text { b. } & \text { motor } & \text { mou1taa2 } \\ & \text { soda } & \text { sou1daa2 } \\ \text { c. } & \text { break } & \text { pik6lik1 } \\ & \text { fluke } & \text { fu6luk1 } \\ \text { d. lace } & \text { lai1si2 } \\ & \text { film } & \text { feillam2 }\end{array}$

Of particular interest here is the adaptation of English initial consonant clusters into Cantonese. English monosyllables with an initial cluster enter Cantonese as disyllables with an L tone (T6) on the first syllable and an $\mathrm{H}$ tone (T1 or T2) on the second (18c). The fact that the epenthetic first syllable in such forms carries T6 instead of T4 thus argues against treating T4 as the default unmarked tone.

In this section, it is shown that the tonal templatic effect observed in reduplicative vocative in Cantonese is largely specific to this morphological construction alone. The next section develops an analysis of tonal transfer (or the lack thereof) in Cantonese vocative reduplication.

\section{Vocative as Morphological Doubling}

Vocative reduplication is analyzed here in terms of double-stem formation (i.e. a form of stem-compounding), where identity holds at the morphosyntactic rather than the phonological level (Inkelas and Zoll 2005), as illustrated in (19). Tone change is governed by a set of tonal alignment constraints (20) associated with the co-phonology $(\varphi)$ of reduplicative vocative stem formation.

(19) Reduplicative vocative construction

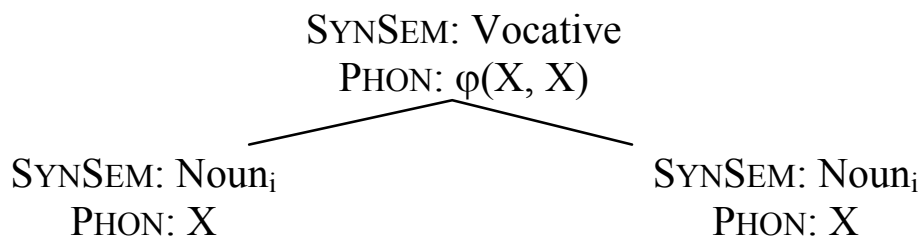

(20) AlignR-T $\{1,2\}$ The right edge of a PrWd must be aligned with the right (ALIGNR) edge of a syllable with $\mathrm{T} 1$ or $\mathrm{T} 2$.

ALIGNL-T4 The left edge of a PrWd must be aligned with the left (ALIGNL) edge of a T4 syllable.

IDENT-ASSOC $_{\mathrm{IO}}$ If there is an association between $x$ and tone $\mathrm{T}$ in the (MAXTONE) input, then there is an association between $x^{\prime}$ and ' $\mathrm{T}^{\prime}$ in the output, where 'x' and T' are the correspondents of $x$ and T respectively (cf. Myers 1997:863; de Lacy 2002:16) 
Thus, when the input contains $\mathrm{T} 4$ syllables, the tone of $\mathrm{R}_{\mathrm{B}}$ must change to $\mathrm{T} 2$ (21a) because the dominating tonal template constraint, ALIGNR-T $\{1,2\}$, which requires the right edge of a PrWd be aligned with the right edge of a syllable with T1 or T2. This constraint must be satisfied even if tonal faithfulness (MAXTONE) is sacrificed. Note that gratuitous tone changes, such as (21c), are not allowed since they do not improve the wellformedness of the reduplicative complex against the tonal template requirements of the vocative reduplication construction.

\begin{tabular}{|ll||l:l|l|}
\hline input & po4, po4 & ALIGNR-T $\{1,2\}$ & ALIGNL-T4 & MAXTONE \\
\hline \hline \multirow{*}{*}{ a. } & {$[\text { po4po2 }]_{\mathrm{PrWd}}$} & & & $*$ \\
\hline b. & {$[$ po4po4] $\mathrm{PrWd}$} & $* !$ & & \\
\hline c. & {$[\text { po2po4] }]_{\mathrm{PrWd}}$} & $* !$ & $*$ & $*$ \\
\hline
\end{tabular}

When the input contains $\mathrm{T} 1$ or $\mathrm{T} 2$, the tone of $\mathrm{R}_{\mathrm{A}}$ must be $\mathrm{T} 4$ (22a) because of another dominating tonal template constraint, ALIGNL-T4, which requires the left edge of a PrWd be aligned with the left edge of a T4 syllable.

\begin{tabular}{|ll|l:l|l|}
\hline input & gol, go1 & ALIGNR-T $\{1,2\}$ & ALIGNL-T4 & MAXTONE \\
\hline \hline \multirow{\sigma}{*}{ a. } & [go4go1 $]_{\mathrm{PrWd}}$ & & & $*$ \\
\hline b. & [go1go1] $\mathrm{PrWd}$ & & $* !$ & $* *$ \\
\hline c. & {$[\text { golgo4] }]_{\mathrm{PrWd}}$} & $* !$ & $*$ & $*$ \\
\hline
\end{tabular}

The analysis thus far shows that tone change is required only when the reduplicative complex would otherwise emerge with tonal specifications that conflict with the templatic requirements of the vocative co-phonology. Total tonal mismatch between the source syllable and the reduplicative complex is observed when the source syllable is associated with tonal specification that does not coincide with tones required by the tonal template constraints. For example, when the tone of the input syllable is T6, candidates that preserve the source tone, either fully (23b) or partially (23c) and (23d), are all rejected as optimal candidates because they violate at least one of the two tonal template constraints.

\begin{tabular}{|c|c|c|c|c|}
\hline input & mui6, mui6 & ALIGNR-T $\{1,2\}$ & ALIGNL-T4 & MAXTONE \\
\hline Fa. & 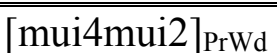 & & & "** \\
\hline b. & [mui6mui6] $]_{\mathrm{PrWd}}$ & $* !$ & * & \\
\hline c. & [mui6mui2] $]_{\text {PrWd }}$ & & $* !$ & * \\
\hline d. & [mui4mui6 $]_{\mathrm{PrWd}}$ & *! & & * \\
\hline
\end{tabular}

Total tonal mismatch is not an absolute requirement when the source syllable carries a tone other than $\mathrm{T} 1, \mathrm{~T} 2$, or $\mathrm{T} 4$, however. Recall that when the source syllable has $T 3$, only $R_{B}$ undergoes tone change. $R_{A}$ retains the $T 3$ specification. Here, I propose that this is due to the presence of a high ranking tonal faithfulness constraint, MAXT3, which requires the preservation of input T3 association. 
(24) MAXT3 If there is an association between $x$ and tone T3 in the input, then there is an association between $x$ ' and T3' in the output, where $\mathrm{x}^{\prime}$ and T3' are the correspondents of $x$ and $\mathrm{T} 3$ respectively

Given that $R_{B}$ undergoes tone change while $R_{A}$ does not, it suggests that MAXT3 is only active when T3 preservation does not conflict with the templatic requirement of ALIGNR-T $\{1,2\}$ (see the losing candidates in (25b) and (25c). The tonal template requirement of ALIGNL-T4 can be sacrificed if tone change on $\mathrm{R}_{\mathrm{A}}$ incurs more violations of MAXT3 than necessary (25a).

\begin{tabular}{|c|c|c|c|c|c|}
\hline input & taai3, taai3 & ALIGNR & MAXT3 & ALIGNL-T4 & MAXTONE \\
\hline a. & [taai3taai2] $]_{\mathrm{PrWd}}$ & & $*$ & $*$ & * \\
\hline b. & 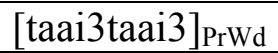 & $* !$ & & * & \\
\hline c. & [taai4taai3] $]_{\mathrm{PrWd}}$ & *! & * & & * \\
\hline d. & [taai4taai2] $]_{\operatorname{PrWd}}$ & & $* * !$ & & ** \\
\hline
\end{tabular}

(26) summarizes the final ranking of the reduplicative vocative co-phonology.

$$
\text { ALIGnR-T }\{1,2\}>>\text { MAXT3 }>>\text { ALIGnL-T4 }>>\text { MAXTone }
$$

The analysis advocated here views the tonal convergence of reduplicative vocative outputs as the results of the idiosyncratic requirements of the co-phonology of vocative reduplication. These tonal template requirements interact with constraints on tonal faithfulness to give rise to the range of observed tonal mapping variation.

\section{Conclusions}

This paper presents a case of non-tonal transfer in reduplication from Cantonese vocative formation. An analysis appealing to the emergence of the unmarked in metrical prominence-driven tonal assignment is rejected for both empirical and theoretical reasons. It is argued that the lack of tonal transfer in vocative reduplication in Cantonese is governed instead by a set of construction-specific tonal templatic requirements. The interaction between these tonal templatic constraints and constraints on tonal faithfulness give rise to the tonal mapping variation observed in this construction. Thus, unlike the case of Bantu reduplication (Downing 2003), the present case study shows that the lack of tonal transfer does not always result from the emergence of the unmarked or variation in the domain of tonal mapping. Morphological construction-specific tonal mapping should be admitted as a possible mechanism for the lack of tonal transfer in certain cases. It is noteworthy that reduplicative faithfulness plays no role in the present analysis because the individual parts of a reduplicative complex are understood to be independent stems that come together as a result of double-stem formation. The individual parts of the reduplicative complex thus do not stand in correspondence relationship with each other. 
Alan C. L. Yu

\section{References}

Bauer, Robert S. and Paul K. Benedict. 1997. Modern Cantonese phonology. Berlin: Mouton de Gruyter.

De Lacy, Paul. 2002. The interaction of tone and stress in Optimality Theory. Phonology 19(1):1-32.

Downing, Laura. 2003. Compounding and tonal non-transfer in Bantu languages. Phonology 20(1):1-42.

Inkelas, Sharon, and Cheryl Zoll. 2005. Reduplication: Doubling in morphology. Cambridge, UK: Cambridge University Press.

Leung, Man-Tak, Sam-Po Law and Suk-Yee Fung. 2004. Type and token frequencies of phonological units in Hong Kong Cantonese. Behavior Research Methods, Instruments, \& Computers 36(3):500-505.

McCarthy, John, and Alan Prince. 1994. The emergence of the unmarked. In M. Gonzalez, ed., Proceedings of the 24th Annual Meeting of North East Linguistic Society, 333-379. Amherst, MA: GLSA.

McCarthy, John, and Alan Prince. 1995. Faithfulness and reduplicative identity. In Jill N. Beckman, Laura Walsh Dickey, and Suzanne C. Urbanczyk, eds., Papers in Optimality Theory, 249-384. Amherst, MA: GLSA.

Myers, Scott. 1997. OCP effects in Optimality Theory. Natural Language and Linguistic Theory 15:847-892.

Odden, David. 1996. Patterns of reduplication in Kikerewe. Ohio State University Working Papers in Linguistics 48:111-149.

Silverman, Daniel. 1992. Multiple scansions in loanword phonology: Evidence from Cantonese. Phonology 9:289-328.

Struijke, Caro. 2000. Why constraint conflict can disappear in reduplication. In Mako Hirotani, ed., Proceedings of the 30th Annual Meeting of North East Linguistic Society. Amherst, MA: GLSA.

Yip, Moira. 1992. The spreading of tonal nodes and tonal features in Chinese dialects. In L. Buszard-Welcher, J. Evans, D. Peterson, L. Wee, and W. Weigel, eds., Proceedings of the 18th Annual Meeting of the Berkeley Linguistics Society (Special Session), 157-166. Berkeley, CA: Berkeley Linguistics Society.

Alan C. L. Yu

Department of Linguistics

University of Chicago

1010 E $59^{\text {th }}$ Street

Chicago, IL 60637

aclyu@uchicago.edu 